\title{
Ability of primary and secondary reproductives to inhibit the development of neotenics in Kalotermes flavicollis (Isoptera: Kalotermitidae)
}

\author{
JIŘí KINDL \\ Institute of Organic Chemistry and Biochemistry, Academy of Sciences of the Czech Republic, Flemingovo nám. 2, 16610 Praha 6, \\ Czech Republic, e-mail: kindl@uochb.cas.cz
}

Key words. Half-orphaned colonies, incipient colonies, inhibition of neotenics, replacement reproductives

\begin{abstract}
The inhibitory potential of primary and secondary reproductives was studied using half-orphaned colonies of Kalotermes flavicollis. Both primary and secondary reproductives (neotenics) were equally effective in inhibiting the development of replacement reproductives. Single females totally inhibited the development of female secondary reproductives but did not affect the development of male secondary reproductives. Single males had neither a stimulatory nor inhibitory effect on the development of secondary reproductives. The inhibitory ability of pairs of primary reproductives shortly after dealation and at the stage of incipient colony formation (couple with the first batch of eggs) was also examined. While pairs of freshly dealated reproductives were not able to inhibit the development of neotenics, pairs of primary reproductives that had their first batch of eggs, fully inhibited the development of neotenics.
\end{abstract}

\section{INTRODUCTION}

The observation that in Kalotermes flavicollis the king and queen prevent the differentiation of neotenics in a colony was published by Grassi \& Sandias (1893) and reviewed by Lüscher $(1974,1977)$ and Springhetti (1985). They supposed that this is achieved by means of inhibitory pheromones. Lüscher also showed that the king and queen possess complementary inhibitory ability (Lüscher, 1952, 1956a, b, 1964), that is, the inhibitory potential is sex specific. According to Lüscher (1956a, b, 1964) neotenic females are capable of inhibiting the differentiation of other female neotenics to a certain extent, and according to Grassé \& Noirot (1960) primary females prevent the development of female neotenics completely. However, there are noticeable gaps in our knowledge of the inhibitory abilities of the male reproductives. While Lüscher (1956a, b, 1964) showed that a sexually mature neotenic male does not inhibit the differentiation of neotenics, Grassé \& Noirot (1960) suggested that a primary male could inhibit the differentiation of male neotenics. Lüscher (1964) also indicated that a functional neotenic male could stimulate the production of female neotenics. Nagin (1972) reported a slightly different action of both sexes in Neotermes jouteli. Functional neotenic females prevented the development of replacement females and had a certain inhibitory effect on the development of replacement males. Single functional neotenic males slightly inhibited the development of both male and female neotenics. The secondary reproductives and their inhibitory effects in other species were reviewed by Myles (1999).

There is an important difference between primary and secondary reproductives, which is linked to their different time of occurrence in the life cycle of the colony. Primary reproductives undergo a solitary phase when initiating a new colony and do not have to exert control over the development of nestmates until the larvae from the first batch of eggs reach the fourth instar. This is the first stage that can differentiate into neotenics (Lüscher, 1952, Kindl, unpubl. observ.). Secondary reproductives are found mostly in mature colonies. They must be able to promptly inhibit their nestmates from differentiating into further neotenics. The maturation of the inhibitory ability of the neotenics has not yet been studied and it is unknown whether the primary reproductives during the first phases of their life can inhibit the development of neotenics.

Lenz (1987) studied the role of "helpers" in Cryptotermes brevis. He added groups of five nymphs to freshly dealated imagoes and in many of these groups some helper nymphs moulted into neotenics. This indicates that not all freshly dealated imagoes are able to prevent the development of neotenics.

The aim of this study was to verify the suggested different inhibitory ability of female and male primary and secondary reproductives, and to determine if freshly dealated imagoes and young primary reproductives in incipient colonies (pair with first batch of eggs) already have some inhibitory ability.

\section{MATERIAL AND METHODS}

\section{Termites}

Half orphaned colonies with neotenics as functional reproductives

Source of termites: Greece, Corfu, Perivoli, colony No. 1, collected 26.v.1999.

Fully functional replacement reproductives with their own offspring, aged more than six months, were used as experimental neotenic pairs. Ten experimental colonies, isolated from the parental colony, were checked daily for one month before the start of the experiment to ensure that the functional neotenics fully inhibited the development of neotenics. 
Half orphaned colonies with imagoes as functional reproductives

Source of termites: Greece, Corfu, Perivoli, colony No. 3, collected 26.v.1999.

Six approximately one-year-old primary pairs were used in this experiment. The incipient colonies consisted of at least ten post fourth instar larvae.

The sex ratio of the initial groups in experiments on half orphaned colonies were not known, but the number of newly developed males was similar in both the experimental (headed by single male or female) and control groups.

Freshly dealated imaginal pairs

Source of TERmites: Italy, Naples, Sabaudia, colony No. 1, collected 25.iv.1998.

Ten pairs of primary reproductives were added to experimental groups within two hours after dealation. This time males and females were kept separately and not allowed to start tandem behaviour. The most active individuals were chosen for the experiment.

Primary pairs at the stage of early colony development

Source of termites: Italy, Naples, Sabaudia, colony No. 4, collected 25.iv.1998.

Experimental groups were added to 10 primary pairs taken from incipient colonies. The colonies were 21 days old and with the first batch of $3-5$ eggs $(3.7 \pm 0.78 ; \mathrm{N}=10)$ at the beginning of the experiment and had from 5 to 9 eggs $(6.6 \pm 1.36 ; \mathrm{N}=10)$ at the end of the experiment.

\section{Experimental conditions}

Termites were kept in Petri dishes $(55 \mathrm{~mm}$ in diameter) and supplied with pieces of spruce (Picea abies) wood ( 2 pieces $30 \times 4 \times 2 \mathrm{~mm}, 2$ pieces $-40 \times 4 \times 2 \mathrm{~mm}, 2$ pieces $-45 \times 4 \times 2 \mathrm{~mm}$ and 1 piece $-50 \times 4 \times 2 \mathrm{~mm}$ ). The pieces of wood were glued by the narrow side to the bottom of the dish $5 \mathrm{~mm}$ apart. An appropriate humidity was maintained by the moist sand at the bottom of the dish and pieces of cellulose wadding, which also served as an additional source of food. The termites were kept in the dark and at $25 \pm 1{ }^{\circ} \mathrm{C}$. Each experimental group consisted of 12 pseudergates and/or full-grown larvae, 8 nymphs and 1 soldier. Orphaned groups of the same composition were used as controls. The groups were checked daily and all new replacement reproductives were removed and sexed. The experiments lasted for 36 days.

\section{Statistics}

Results were analysed using non-parametric tests. KruskalWallis test and Dunn's Multiple Comparison Test were used for experiments on half orphaned colonies (sexes were analysed separately), and Mann-Whitney U test for experiments on imagoes in incipient colonies. All analyses employed GraphPad Prism version 3.00 for Windows, GraphPad Software, San Diego California USA, www.graphpad.com.

\section{RESULTS}

\section{Half orphaned colonies with neotenics as functional reproductives}

Production of female neotenics

Neotenic females totally inhibited the development of other female neotenics (Kruskal-Wallis test, $\mathrm{H}=20.67$, $\mathrm{P}<0.0001)$. Neotenic males did not affect development of female neotenics (Fig. 1). There was no significant difference in the number of female neotenics that developed

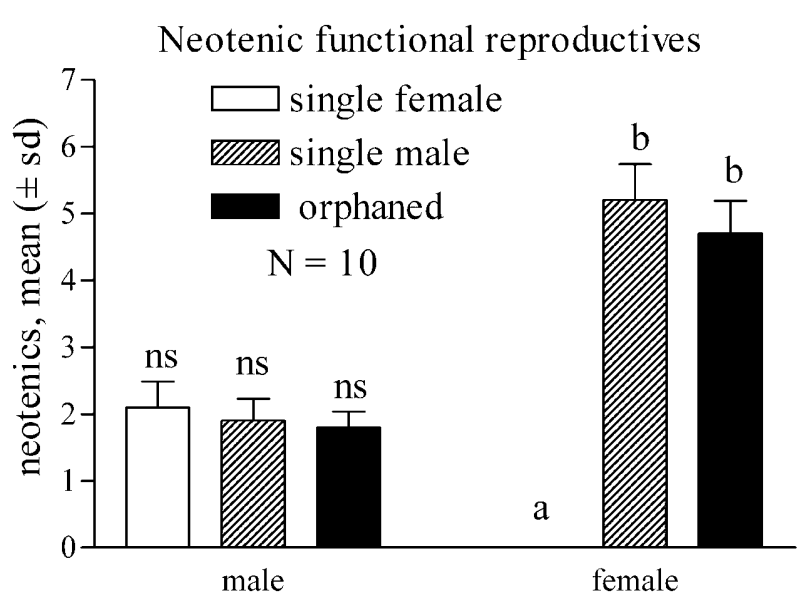

Fig. 1. Half orphaned colonies with neotenic reproductives. Sexes were analysed separately. There was no significant difference in the number of male neotenics that developed in the groups with a single male, single female or in orphaned control (Kruskal-Wallis test, $\mathrm{H}=0.3605, \mathrm{P}=0.8350$ ). Neotenic females inhibited the development of female neotenics (Kruskal-Wallis test, $\mathrm{H}=20.67, \mathrm{P}<0.0001)$. Columns with the same letter are not significantly different. Dunn's Multiple Comparison Test.

in groups with a single male or totally orphaned control (Dunn's Multiple Comparison Test, $\mathrm{P}>0.05$ ).

Production of male neotenics

There was no significant difference in the number of male neotenics that developed in groups with a single male, single female or totally orphaned control (KruskalWallis test, $\mathrm{H}=0.3605, \mathrm{P}=0.8350$ ).

\section{Half-orphaned colonies with imagoes as functional reproductives}

The pattern of neotenic production under the influence of imagoes was similar to that reported above for neotenics (Fig. 2).

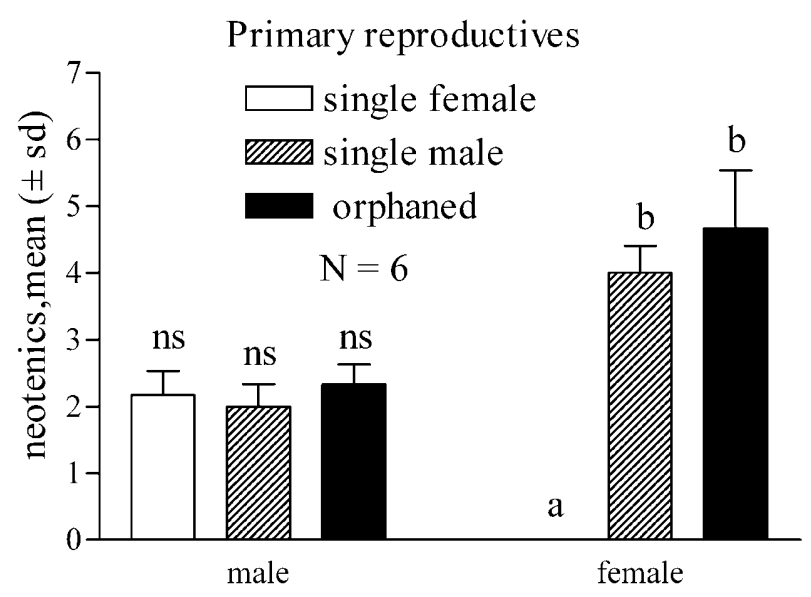

Fig. 2. Half orphaned colonies with primary reproductives. Sexes were analysed separately. There was no significant difference in the number of male neotenics that developed in the groups with a single male, single female or orphaned control (Kruskal-Wallis test, $\mathrm{H}=0.2618, \mathrm{P}=0.8773$ ). Primary females inhibited the development of neotenic females (Kruskal-Wallis test, $\mathrm{H}=12.16, \mathrm{P}=0.0023$ ). Columns with the same letter are not significantly different. Dunn's Multiple Comparison Test. 
Freshly dealated primary reproductives

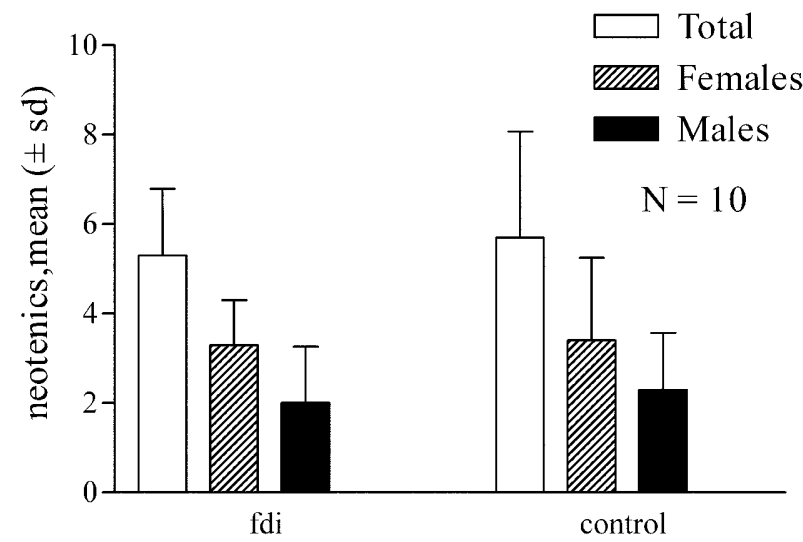

Fig. 3. Inhibitory potential of freshly dealated imaginal pairs (fdi). There was no significant difference between experimental and control (orphaned) groups. Mann-Whitney $\mathrm{U}$ test, $\mathrm{F}=49, \mathrm{P}$ $=0.9705$. (Analysis was done on the pooled data for both sexes of neotenics).

\section{Production of female neotenics}

Primary females prevented the differentiation of female neotenics (Kruskal-Wallis test, $\mathrm{H}=12.16, \mathrm{P}=0.0023$ ). Primary males did not affect the development of female neotenics. There was no significant difference in the number of female neotenics that developed in groups with a single male or totally orphaned control (Dunn's Multiple Comparison Test, $\mathrm{P}>0.05$ ).

\section{Production of male neotenics}

There was no significant difference in the numbers of male neotenics that developed in groups with a single male, single female or totally orphaned control (KruskalWallis test, $\mathrm{H}=0.2618, \mathrm{P}=0.8773$ ).

\section{Freshly dealated imaginal pairs}

Freshly dealated primary pairs did not inhibit the development of neotenics (Fig. 3). There was no significant

Primary reproductives at the stage of incipient colony

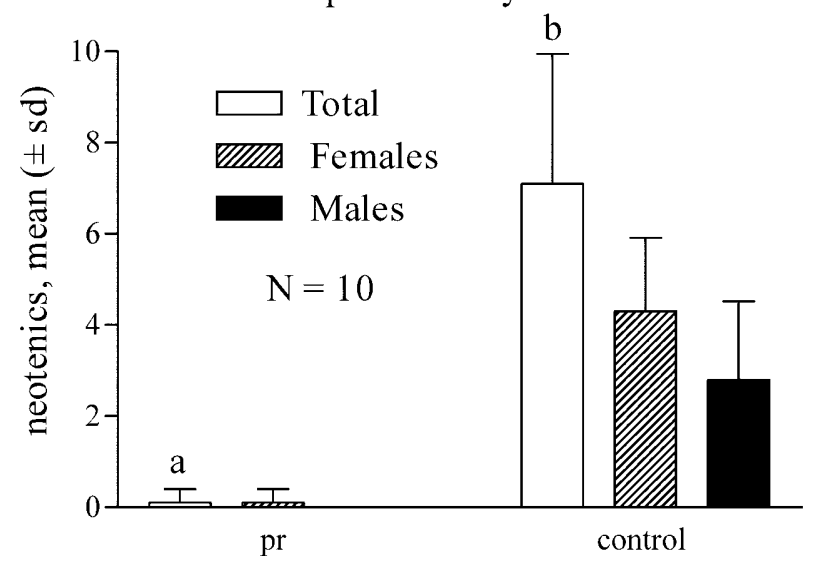

Fig. 4. Inhibitory potential of primary reproductives at the stage of early colony development (pr). Pairs of primary reproductives at the incipient stage of colony growth inhibited the development of neotenic reproductives. Control - orphaned groups. Mann-Whitney $\mathrm{U}$ test, $\mathrm{F}=0.50, \mathrm{P}<0.001$. (Analysis was done on the pooled data for both sexes of neotenics). difference between the experimental and control groups (Mann-Whitney $\mathrm{U}$ test, $\mathrm{U}=49, \mathrm{P}=0.9705$ ). The males and females did not behave as couples. Their abdomens remained flat. Oviposition was not recorded during the experiment.

\section{Primary pairs at the stage of early colony development}

Primary pairs at the incipient colony stage inhibited the development of neotenic reproductives (Fig. 4). There was only one exception: in one replicate, a single female neotenic was recorded on the $7^{\text {th }}$ day of the experiment (Mann-Whitney $\mathrm{U}$ test, $\mathrm{U}=0.50, \mathrm{P}<0.001$ ).

\section{DISCUSSION}

In K. flavicollis the loss of one or both reproductives triggers larvae of $4^{\text {th }}$ and older instars, nymphs and pseudergates to develop into replacement reproductives. As a rule more than one pair of neotenics develops. The replacement reproductives fight among themselves and usually only one pair survives. Surplus neotenics are either killed or injured and are subsequently eaten by nestmates (Rupli, 1969). Both primary and secondary female reproductives are not physogastric. A neotenic female of $K$. flavicollis has the same type of ovaries with seven ovarioles as a primary reproductive and their fecundity seems to be similar (Noirot, 1990). That is, the primary and secondary reproductives are functionally equivalent.

My results confirm that females specifically inhibit the development of female neotenics (in colonies with primary or neotenic reproductives) and do not support the conclusion of Grassé \& Noirot (1960) that primary males of Kalotermes flavicollis specifically inhibit the development of male neotenics. The data showed no difference in the effect of primary or neotenic male reproductives on the development of male neotenics. Grassé \& Noirot (1960) did not remove newly developed neotenics during their experiment, which was checked after 10,20 and 40 days. Thus, they did not take into account the possibility that the primary king may have eliminated newly developed neotenics. Grassé \& Noirot (1960) showed that differentiation of male neotenics was prevented when 2 males were present in a group. This inhibition occurred in their experiments with groups consisting only of pseudergates of male sex (experiment with neotenics), but not in those with primary males as functional reproductives and pseudergates of both sexes. Moreover the inhibition might have been a result of both elimination and lack of further male neuters in the competent period to moult into neotenics. Lüscher (1964) also claimed that although one neotenic male had no power of inhibition, two males seemed to inhibit to a certain degree the differentiation of male neotenics. Somewhat stronger actions of two male neotenics are recorded in Neotermes jouteli (Nagin, 1972). The development of new neotenics of both sexes was strongly suppressed. Unfortunately there was only one replication of this experiment. The inhibition by two males might be explained by their reciprocal stimulation, which mimics that of the functional female. 
The fact, that imagoes at the incipient colony growth stage are able to inhibit the differentiation of replacement reproductives, also supports the idea of the functional equality of the primary reproductives and neotenics. It also suggests that this inhibitory system might have some other role, for instance in the communication between male and female. However, this hypothesis requires further study.

According to Maistrello \& Sbrenna $(1998,1999)$ there is a gender based behavioural specialisation in the reproductives of $K$. flavicollis. The male is the most active in vibratory acts and rate and range of social contacts. The male seems to play a key role in the determination of the social structure and development of the colony, acting as a mediator in the social interactions between the female and other members of the colony. These findings explain the complementary role of the male in the inhibition of development of neotenics by a functional pair. A male alone has no effect but together with the female inhibits the development of male neotenics and helps to spread the postulated female's pheromone. The female may stimulate the male to produce his inhibitory pheromone. Only the presence of both sexes can prevent the development of new male neotenics.

Contrary to the results of Lüscher (1964), neither primary nor neotenic males in half orphaned colonies stimulated the development of female neotenics. In previous papers of Lüscher $(1952,1956)$, there is no indication of such male stimulation effect and the inhibitory potential of female neotenics is not absolute. However, there is no information on the age and physiological conditions of the neotenics used in these studies, which if too young, could have lacked their inhibitory ability at the beginning of the experiment.

Lenz (1987) mentions poor inhibitory ability of the freshly dealated imagoes of Cryptotermes brevis, which agrees with the result presented in this paper. It seems that it is necessary for imagoes to mature sexually before they are able to inhibit the development of neotenics. Myles \& Chang (1984) hypothesised that pheromonal inhibition is related to physiological changes in mature females, associated with egg production. Hewitt \& Nel (1969), Hewitt et al. (1972) and Watson et al. (1972) showed that in Hodotermes mossambicus the maturation of primary reproductives depends on the shift from living in a group (natal nest) to living as a pair, and especially on the reduced number of body contacts perceived by antennae. Adding 20 pseudergates and nymphs to freshly dealated pairs seemed to mimic the social conditions of a colony and prevented them from maturing and developing an inhibitory ability.

ACKNOWLEDGEMENTS. I wish to thank I. Hrdý, M. Lenz and two anonymous referees for valuable comments on the manuscript. This work was supported by grant No S4055104 GA of Academy of Sciences of the Czech Republic and research project Z4 -055-905 (Academy of Sciences of the Czech Republic).

\section{REFERENCES}

Grassé P.P. \& NoIrot C. 1960: Rôle respectif des mâles et des femelles dans la formation des sexués néoténiques chez Calotermes flavicollis. Insectes Soc. 7: 109-123.

Grassi B. \& SANDias A. 1893: Constituzione e sviluppo della societá die termitidi. Atti. Accad. Gioenia Sci. Nat. 6/7: $1-150$.

HewitT P.H. \& NeL J.C.C. 1969: The influence of group size on the sarcosomal activity and the behaviour of Hodotermes mossambicus alate termites. J. Insect Physiol. 15: 2169-2177.

Hewitt P.H., Watson J.A.L., Nel J.C.C. \& Schoeman I. 1972: Control of the change from group to pair behaviour by Hodotermes mossambicus reproductives. J. Insect Physiol. 18: $143-150$.

LENZ M. 1987: Brood production by imaginal and neotenic pairs of Cryptotermes brevis (Walker): The significance of helpers (Isoptera: Kalotermitidae). Sociobiology 13(2): 59-66.

LÜSCHER M. 1952: Die Produktion und Elimination von Ersatzgeschlechtstieren bei der Termite Kalotermes flavicollis Fabr. Z. Vergl. Physiol. 34: 123-141.

LÜSCHER M. 1956a: Die Entstehung von Ersatzgeschlechtstieren bei der Termite Kalotermes flavicollis Fabr. Insectes Soc. 3: 119-128.

LÜSCHER M. 1956b: Hemmende und fördernde Faktoren bei der Entstehung von Ersatzgeschlechtstieren bei der Termite Kalotermes flavicollis Fabr. Rev. Suisse Zool. 63: 261-267.

LÜSCHER M. 1964: Die spezifische Wirkung männlicher und weiblicher Ersatzgeschlechtstiere auf die Entstehung von Ersatzgeschlechtstieren bei der Termite Kalotermes flavicollis (Fabr.). Insectes Soc. 11: 79-90.

LüsCHER M. 1974: Kasten und Kastendifferenzierung bei niederen Termiten. In Schmidt G.H. (ed): Socialpolymorphismus bei Insekten. Wissenschaftl. Verlaganst., Stuttgart, pp. 694-739.

Lüscher M. 1977: Queen Dominance in Termites. Proc. VIIIth Congr. I.U.S.S.I. Wageningen. pp. 238-242.

Maistrello L. \& Sbrenna G. 1998: Behavioral profiles in laboratory colonies of Kalotermes flavicollis (Isoptera: Kalotermitidae) with different social environments. Sociobiology 31: 91-104.

Maistrello L. \& Sbrenna G. 1999: Behavioural differences between male and female replacement reproductives in Kalotermes flavicollis (Isoptera: Kalotermitidae). Insectes Soc. 46: 186-191.

Myles T.G. \& Chang F. 1984: The caste system and caste mechanism of Neotermes connexus (Isoptera: Kalotermitidae). Sociobiology 9(3): 163-321.

Myles T.G. 1999: Review of secondary reproductives in termites (Insecta: Isoptera) with comments on its role in termite ecology and social evolution. Sociobiology 33(1): 1-91.

NAGIN R. 1972: Caste determination in Neotermes jouteli (Banks). Insectes Soc. 19: 39-61.

NorRot C. 1990: Sexual castes and reproductive strategies in termites. In Engels W. (ed.): Social Insects, an Evolutionary Approach to Castes and Reproduction. Springer-Verlag, Berlin, Heidelberg, New York, pp. 5-35.

Rupli E. 1969: Die Elimination überzähliger Ersatzgeschlechtstiere bei der Termite Kalotermes flavicollis Fabr. Insectes Soc. 16: 235-248.

SpRINGHETti A. 1985: The function of the royal pair in the society of Kalotermes flavicollis (Fabr.) (Isoptera: Kalotermitidae). In Watson J.A.L., Okot-Kotber B.M. \& Noirot C. (eds): Caste Differentiation in Social Insects. Pergamon Press, Oxford, pp. 165-175.

Watson J.A.L., Nel J.C.C. \& HewitT P.H. 1972: Behavioural changes in founding pairs of the termite Hodotermes mossambicus. J. Insect Physiol. 18: 373-387.

Received November 3, 2003; revised January 29, 2004; accepted March 4, 2004 